\title{
Penerapan metode variativ dalam meningkatkan pembelajaran Bahasa Indonesia di SMP Buru
}

\author{
Harziko Harziko ${ }^{1}$, Yulis Mayanti², Karim ${ }^{3}$, Azwan ${ }^{4}$, Musyawir ${ }^{5}$, Risman lye ${ }^{6^{*}}$ \\ 1,2,3 4,5,6 Universitas Iqra Buru, Indonesia \\ "Korespondensi: rismaniye@gmail.com
}

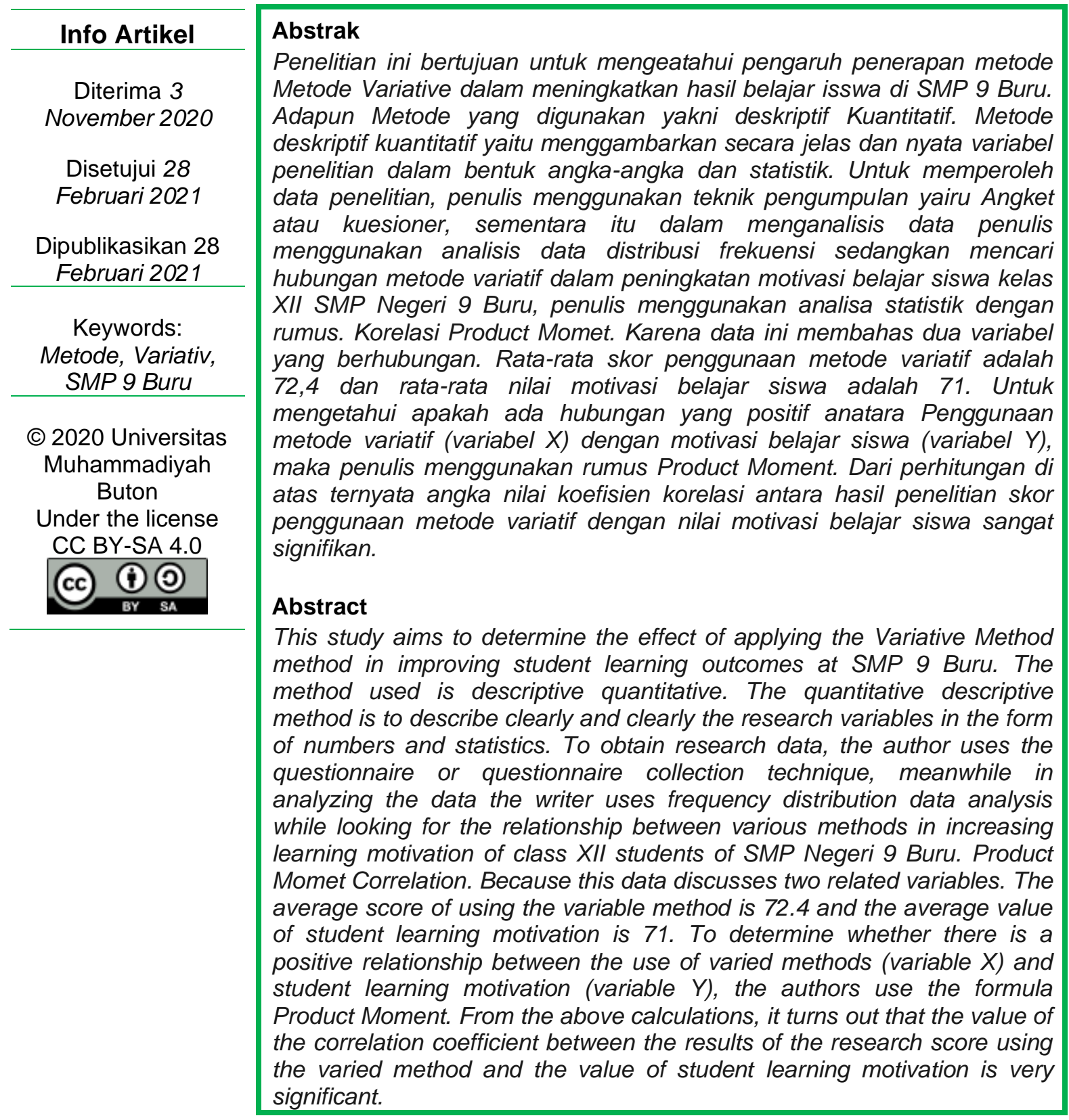




\section{Pendahuluan}

Kunci keberhasilan pembangunan sekarang pada masa kini dan nanti untuk indonesia terletak pada pendidikan. Untuk itu pendidikan memerlukan peranan penting bagi pendidik untuk menunjukkan skil dan kemampuan mereka kepada peserta didik. Melalui pendidikan ini diharapkan setiapo individu atau peserta didik mampu bersaing dikancah nasional maupun internasional. Perkembangan Iptek di era sekarang terutama bidang teknologi dan ilmu pengetahuan maka pendidikan nasional juga harus terus dkembangkan mengingat pendidikan adalah tombak penting majunya suatu bangsa. mutu pembelajaran di sekolah. Penyusunan kurikulum berbasis kompetensi (KBK) direvisi melalui kurikulum tingkat satuan pendidikan (KTSP). Kurikulum K-13 yang ada saat ini menuntut adanya pergeseran paradigma dalam pendidikan dan pembelajaran, khususnya jenis dan jenjang pendidikan formal (pendidikan sekolah). Peningkatan mutu pendidikan tentunya tidak terlepas dari upaya peningkatan erubahan ini juga harus dilakukan oleh para guru yang bertanggung jawab dalam menyelenggarakan pembelajaran sekolah. (Afida, 2014), oleh karena itu, guru dituntut memiliki kemampuan menyesuaikan elemen pembelajaran agar dapat menjalin keterkaitan dengan fungsi elemen lainnya.

Di Indonesia sendiri, pendidikan telah mengalami berbagai perubahan, terlihat dari kurikulum bahwa argumentasi lebih merupakan kurikulum yang perlu diganti karena tidak sesuai dengan jaman atau jaman sekarang, oleh karena itu perlu diubah. Selain itu, pendidikan modern membutuhkan hal-hal baru, karena khususnya pembelajaran dan pengajaran di sekolah berbeda-beda sesuai dengan materi, media dan metode yang digunakan. Pembelajaran konvensional saat ini membuat siswa merasa bosan dengan proses pembelajarannya, sehingga diperlukan pembelajaran yang menarik perhatian siswa khususnya dalam pendidikan sekolah.

Status bahasa Indonesia sebagai bahasa nasional berperan sebagai bahasa pengantar di lembaga pendidikan, pembina budaya, pembina iptek, dan sarana komunikasi untuk pemerintah dan kepentingan nasional (Susiati, lye, 2018) Mengingat permasalahan di atas, Penulis mencoba memberikan solusi dengan menerapkan berbagai metode pembelajaran yang tentunya merupakan upaya untuk meningkatkan hasil belajar siswa. Gunakan berbagai metode pembelajaran untuk berusaha mempertahankan dan meningkatkan perhatian dan motivasi siswa agar tetap aktif dalam proses pembelajaran.

Pengajaran bahasa Indonesia bertujuan untuk mengambangkan kemampuan menggunakan bahasa Indonesia dalam segala fungsinya, yaitu sebagai sarana komunikasi, sarana, berpikir/bernalar, sarana persatuan, dan sarana kebudayaan. Kemudian pembelajaran bahasa Indonesia juga mempunyai sasaran, "sasaran pembinaan bahasa Indonesia bagi siswa SMP ialah (1) agar siswa memiliki kemampuan berbahasa Indonesia yang baik dan benar, (2) dapat menghayati bahasa dan sastra Indonesia". Sabarti, dalam (Susiati, lye, 2018) Metode pembelajaran variatif yang dimaksud dalam penelitian ini adalah kombinasi penggunaan beberapa metode pembelajaran secara bervariasi sebagai upaya meningkatkan hasil belajar Bahasa Indonesia siswa. Sebagai contoh, diawal pembelajaran menggunakan metode ceramah kemudian diselingi dengan metode tanya jawab sehingga siswa akan mempunyai keseriusan dalam memperhatikan pelajaran, kemudian pelajaran diakhiri dengan pemberian kuiz untuk mengetahui 
sejauh mana pemahaman siswa (Hadi, 2004). Dalam penerapan metode pembelajaran variatif ini, tentunya dipadukan dengan keterampilan mengadakan variasi dalam proses belajar mengajar yang meliputi tiga aspek, yaitu: a) Variasi dalam gaya mengajar. b) Variasi dalam menggunakan media dan bahan pengajar; dan c) Variasai dalam interaksi antara guru dengan siswa.

Penggunaan Variasi metode, dan media yang dapat didengar, dilihat, disentuh atau dimanipulasi juga berbeda. Mode interaksi antara guru dan siswa bisa antara individu guru dengan siswa, antara guru dan siswa secara berkelompok, dan juga Dapat memberikan kesempatan kepada siswa untuk saling berinteraksi dalam memahami topik. (Hamdu 2011) Adapun materi dalam penelitian ini adalah Memahami siaran atau cerita yang disampaikan secara langsung /tidak langsung yaitu: Metode Ceramah dilakukan awal setelah membuka pelajaran, sehingga siswa akan mendengarkan Isi pelajaran berdasaran RPP. Metode Diskusi, setelah melakukan metode ceramah, maka siswa dituntut untuk mampu berbicara melalui sistim diskusi. Metode Tanya Jawab, setelah melakukan metode ceramah, kemudian siswa di tuntut untuk melakukan Tanya jawab, dalam mengembangkan potensi kemampuan berbicara. Metode Pemberian Hukuman, agar siswa mampu menelaah inti permasalahan dalam materi-materi inti yang diberikan. Materi metode variatif yaitu: Rekaman cerita, tuturan langsung (kaset, CD, buku cerita), unsur intrinsik (tema, alur, konflik, penokohan, sudut pandang, dan amanat), dan unsur ekstrinsik (agama, politik, sejarah, budaya).

Adapun yang menjadi rumusan masalah pada penelitian ini yakni, maka yang menjadi pokok masalah dalam penelitian aadalah bagaimanakan penerapan metode variativ dalam meningkatkan pembelajatran bahasa indonesia di SMPN 9 buru dan pengaruh penerapan metode variativ dalam meningkatkan motivasi belajar siswa.

\section{Metode}

Metode yang digunakan dalam penelitian ini adalah metode penelitian kuantitatif deskriptif. Metode deskripsi kuantitatif merupakan desain penelitian yang dapat mendeskripsikan variabel penelitian secara jelas dalam bentuk numerik dan statistik. (Martono 2011). Jenis penelitian yang dilakukan peneliti adalah penelitian lapangan yang diarahkan langsung pada objek penelitian. Untuk memperoleh data-data lapangan ini, penulis menggunakan teknik pengumpulan data sebagai berikut: Angket atau kuesioner, yaitu merupakan suatu daftar atau rangkaian pertanyaan yang disusun secara tertulis mengenai sesuatu yang berkaitan dengan penelitian (Martono, 2011) Angket yang digunakan adalah tipe pilihan (tertutup).

Didasarkan pada perlakukan objek penelitian. Selanjutnya digunakan rancangan kuantitatif karena data yang menjadi penelitian adalah siswa kelas VII SMP 9 Buru, dalam pendeskripsiannya menggunakan statistic deskriptif, yakni berupa rata-rata hitung dan persentase.

Desain penelitian ini terdiri dari dua variabel yaitu variabel bebas $(x)$ dan terikat (y). metode variatif $(\mathrm{x})$ dan Motivasi Belajar (y).

$(\mathrm{x}$ y) 
Instrumen penelitian ini berupa hasil metode variatif dalam peningkatan motivasi belajar yang meliputi:

1. Penentuan metode variatif yaitu:

a. Metode Ceramah dilakukan awal setelah membuka pelajaran, sehingga siswa akan mendengarkan Isi pelajaran berdasaran RPP.

b. Metode Diskusi, setelah melakukan metode ceramah, maka siswa dituntut untuk mampu berbicara melalui sistim diskusi.

c. Metode Tanya Jawab, setelah melakukan metode ceramah, kemudian siswa di tuntut untuk melakukan Tanya jawab, dalam mengembangkan potensi kemampuan berbicara.

d. Metode Pemberian Hukuman, agar siswa mampu menelaah inti permasalahan dalam materi-materi inti yang diberikan.

e. Materi metode variatif adalah. rekaman cerita, tuturan langsung, (buku cerita, kaset CD). Unsur intrinsic (tema, alur, konflik penokohan, sudut pandang dan, unsur ekstrinsik yaitu (agama politik,) (Hamdu, 2011).

Angket motivasi belajar siswa kelas VII SMP Negeri 9 Buru

Prosedur yang diterapkan saat pengadaan instrumen yang baik adalah merencanakan dan menyiapkan bahan uji dan penganalisaan hasil (Martono, 2011). Angket yang dimaksud adalah motivasi belajar siswa kelas VII SMP Negeri 9 Buru. Dengan empat item jawaban yaitu: sangat setuju (SS), setuju (S), tidak setuju (TS), sangat tidak setuju (STS)

Untuk analisa data, penulis menggunakan analisa data distribusi frekuensi, sedangkan mencari hubungan metode variatif dalam peningkatan motivasi belajar siswa kelas VII SMP 9 Buru, penulis menggunakan analisa statistik dengan rumus. Korelasi Product Momet. Karena data ini membahas dua variabel yang berhubungan. Secara operasional analisis data teknik korelasi dilakukan melalui tahapan berikut:

Mencari anka korelasi dengan rumus:

$r x y=\frac{N \sum x y-\left(\sum x\right)\left(\sum y\right)^{2}}{\sqrt{\left[N \Sigma y^{2}-\Sigma y^{2}\right]\left[N \sum y^{2}-\left(\sum y\right)^{2}\right]}}$

Keterangan:

Rxy: Angka indeks. r. produk moment antara variabel $X$ dan $Y$

$\mathrm{N}$ : Jumlah respon

$\sum X Y$ : Jumlah hasil perkalian antara skor $X$ dan $Y$

$\Sigma \mathrm{X}$ : Jumlah seluruh skor $\mathrm{X}$

$\sum Y$ : Jumlah seluruh skor $Y$

Kemudian Interpretasi Secara Sederhana Anas, dalam (Susiati, S., Iye, R., 2019) memberikan interpretasi secara sederhana terhadap Angka Indeks Korelasi.r. Product Moment (rxy), pada umumnya dipergunakan pedoman sebagai berikut: 
Tabel 1. Angka Indeks Korelasi.r. Product Moment (rxy)

\begin{tabular}{ll}
$\begin{array}{l}\text { Besarnya } \\
\text { r. Product Moment }\end{array}$ & \multicolumn{1}{c}{ Interpretasi } \\
\hline $0,00 \cdot 0.20$ & $\begin{array}{l}\text { Antara variabel } \mathrm{X} \text { dan variabel } \mathrm{Y} \text { memang terdapat } \\
\text { korelasi, akan tetapi korelasi itu sangat lemah atau } \\
\text { rendah sehingga korelasi itu diabaikan (dianggap tidak } \\
\text { ada korelasi antara variabel } \mathrm{X} \text { dan variabel } \mathrm{Y} \text { ). }\end{array}$ \\
\hline $0,20 \cdot 0,40$ & $\begin{array}{l}\text { Antara variabel } \mathrm{X} \text { dan variabel } \mathrm{Y} \text { terdapat korelasi yang } \\
\text { lemah atau yang rendah. }\end{array}$ \\
\hline $0,40 \cdot 0,70$ & $\begin{array}{l}\text { Antara variabel } \mathrm{X} \text { dan variabel } \mathrm{Y} \text { terdapat korelasi yang } \\
\text { sedang atau cukup. }\end{array}$ \\
\hline $0,70 \cdot 0,90$ & $\begin{array}{l}\text { Antara variabel } \mathrm{X} \text { dan variabel } \mathrm{Y} \text { terdapat korelasi yang } \\
\text { kuat atau tinggi. }\end{array}$ \\
\hline $0,90.1,00$ & $\begin{array}{l}\text { Antara variabel } \mathrm{X} \text { dan variabel } \mathrm{Y} \text { terdapat korelasi yang } \\
\text { sangat kuat atau sangat tinggi. }\end{array}$
\end{tabular}

Salah satu teknik pengumpulan data yang digunakan dalam penelitian ini adalah menggunakan angket yang disebarkan pada responden berdasarkan sampel. Kemudian data yang diperoleh diolah dalam bentuk tabel distribusi frekuensi dengan menggunakan rumus;

$P=\frac{f}{N} x 100 \%$

$\mathrm{P}=$ Persentase yang dicari

$\mathrm{F}=$ Frekuensi

$\mathrm{N}=$ Number of cases

Dengan ketentuan skala prosentase sebagai berikut

Tabel 2. Distribusi Frekuensi

\begin{tabular}{lll}
\hline No & \multicolumn{1}{c}{ Presentase } & \multicolumn{1}{c}{ Penafsiran } \\
& & \\
\hline 1 & $60 \%-99 \%$ & Sebagian Besar \\
2 & $51 \%-59 \%$ & Lebih dari Setengahnya \\
3 & $50 \%-49 \%$ & Setengahnya \\
4 & $40 \%-49 \%$ & Hampir Setengahnya \\
5 & $1 \%-39 \%$ & Sebagian Kecil \\
\hline
\end{tabular}

\section{PEMBAHASAN}

Hasil angket dimasukkan dalam tabulasi yang merupakan proses data dan instrumen pengumpulan data (Tes Meode Variatif), Selanjutnya ditentukan hasil insturmen tes nilai metode variatif, dalam sebuah tabel sebagai berikut:

Tabel 3. Nilai Penggunaan Metode Variatif 


\begin{tabular}{ccccccc}
\hline & $\begin{array}{c}\text { Kode } \\
\text { Sampel }\end{array}$ & Ceramah & Diskusi & $\begin{array}{c}\text { Tanya } \\
\text { Jawab }\end{array}$ & $\begin{array}{c}\text { Pemberian } \\
\text { Hukuman }\end{array}$ & $\begin{array}{c}\text { Hasil } \\
\text { Rekapitulasi }\end{array}$ \\
\hline 1 & 001 & 90 & 90 & 90 & 70 & 85 \\
\hline 2 & 002 & 70 & 60 & 70 & 80 & 70 \\
\hline 3 & 003 & 70 & 60 & 70 & 80 & 70 \\
\hline 4 & 004 & 100 & 80 & 90 & 80 & 88 \\
\hline 5 & 005 & 60 & 60 & 70 & 70 & 65 \\
\hline 6 & 006 & 90 & 90 & 70 & 90 & 85 \\
\hline 7 & 007 & 60 & 80 & 70 & 80 & 73 \\
\hline 8 & 008 & 60 & 60 & 50 & 60 & 58 \\
\hline 9 & 009 & 60 & 60 & 50 & 60 & 58 \\
\hline 10 & 010 & 60 & 70 & 60 & 60 & 63 \\
\hline 11 & 011 & 60 & 80 & 60 & 80 & 70 \\
\hline 12 & 012 & 70 & 70 & 50 & 80 & 75 \\
\hline 13 & 013 & 90 & 90 & 90 & 80 & 85 \\
\hline 14 & 014 & 90 & 80 & 90 & 90 & 85 \\
\hline 15 & 015 & 70 & 80 & 70 & 90 & 78 \\
\hline
\end{tabular}

\section{Sumber: Hasil Tes Metode Variatif}

Dari perhitungan di atas ternyata angka nilai koefisien korelasi antara hasil penelitian skor penggunaan metode variatif dengan nilai motivasi belajar siswa sebesar 0,605. Selanjutnya untuk mengetahui apakah ada hubungan yang positif atau tidak, maka $r$ hasil perhitungan dibandingkan dengan.r. tabel.

Tabel 4. Motivasi Belajar Siswa

\begin{tabular}{lccc}
\hline No & $\begin{array}{c}\text { Nomor } \\
\text { Responden }\end{array}$ & $\begin{array}{c}\text { Metode } \\
\text { Variativ } \\
\mathbf{X}\end{array}$ & $\begin{array}{c}\text { Metode } \\
\text { Variativ } \\
\mathbf{Y}\end{array}$ \\
\hline 1 & 001 & 85 & 65 \\
\hline 2 & 002 & 70 & 66 \\
\hline 3 & 003 & 70 & 71 \\
\hline 4 & 004 & 88 & 64 \\
\hline 5 & 005 & 65 & 61 \\
\hline 6 & 006 & 85 & 67 \\
\hline 7 & 007 & 73 & 71 \\
\hline 8 & 008 & 58 & 71 \\
\hline 10 & 009 & 58 & 70 \\
\hline 11 & 010 & 63 & 69 \\
\hline 12 & 011 & 70 & 70 \\
\hline 13 & 012 & 75 & 69 \\
\hline 14 & 013 & 85 & 65 \\
\hline 15 & 014 & 70 & 66 \\
\hline & 015 & 70 & 71 \\
\hline
\end{tabular}

Dari data tabel di atas jumlah total dari skor penggunaan metode variatif dalam meningkatkan motivasi belajar siswa adalah 1085 sehingga rata-rata nilainya adalah:

$M x=\frac{\sum X}{N}=\frac{1085}{15}=72,4$ 
$\mathrm{Mx}=$ Rata-rata nilai angket

$\Sigma \mathrm{X}=$ Jumlah total dari nilai angket

$\mathrm{N}=$ Jumlah Siswa

Sedangkan jumlah total dari nilai motivasi belajar siswa adalah 1065, sehingga rata-rata nilai prestasi belajar dapat dihitung sebagai berikut:

Jadi rata-rata skor penggunaan metode variatif adalah 72,4 dan rata-rata nilai motivasi belajar siswa adalah 71 .

Seperti telah dikemukakan pada hasil penelitian di atas dalam memberikan interpreasi terhadap rxy atau ro dapat ditempuh dengan cara, Interpretasi secara sederhana yaitu: Dari perhitungan di atas, telah diperoleh rxy sebesar 0,605. Jika diperhatikan, maka Angka Indeks Korelasi yang telah diperoleh tidak bertanda negatif. Ini berarti korelasi antara variabel $X$ (penggunaan metode variatif) dengan variabel $Y$ (motivasi belajar siswa) terdapat hubungan yang searah; dengan istilah lain: terdapat korelasi yang positif diantara kedua variabel tersebut. Apabila dilihat besarnya rxy yang diperoleh ini, yaitu: 0,605 ternyata terletak antara 0,40. 0,70. dapat dinyatakan bahwa korelasi antara variabel $X$ dan variabel $Y$ ialah korelasi yang tergolong sedang atau cukup. Dengan demikian secara sederhana dapat penulis berikan interpretasi terhadap rxy tersebut, yaitu bahwa terdapat korelasi positif yang signifikan antara variabel $X$ dan variabel $Y$.

\section{Kesimpulan}

Berdasarkan hasil penelitian maka dapat disimpulkan bahwa penggunaan metode fariativ pada siswa SMP 9 Buru sangat evisisen dalam hal ini memepengaruhui peningkatan motivasi belajar siswa. dapun saran penulis dalam penelitian ini yaitu Untuk para guru, karena sekolah merupakan lembaga pendidikan setelah keluarga hendaklah memperhatikan perkembangan siswa terutama yang mempunyai pestasi rendah atau mempunyai kesulitan dalam belajar dan dalam proses belajar mengajar seharusnya guru mempunyai metode yang kaya dalam menunjang prestasi siswa di Sekolah.

\section{Ucapan Terima Kasih}

Penelitian ini didanai oleh Kementreian pendidikan dan Kebudayaan Republik Indonesia dalam ham Ini RISTEKBRIN, Untuk penelti mengucapkan banyak terimah kasih atas dana yang telah diberikan kepada peneliti sehingga penelitian ini dapat terselsaikan dengan baik. Begitupula Dinas Pendidikan Kabupaten Buru khususnya SMP 9 Buru.

\section{Daftar Pustaka}

Afida, N. (2014). Analisis Faktor-Faktor yang mempengaruhi Prestasi Belajar Siswa Kelas X SMA AL-Islam Krian. Statistika. Jurnal IImiah Dan Aplikasi Statistika, 6(1).

Hadi, S. (2004). Metodologi research jilid I. Yogyakarta: Andi. https://doi.org/10.1038/emboj.2012.81 
Hamdu. (2011). Pengaruh Motivasi Belajar Siswa Terhadap Presatsi Belajar IPA di Sekolah Dasar. Jurnal Penelitian Pendidikan, 12(1).

Martono, N. (2011). Metode Penelitian Kuantitatif. Jakarta: PT Raya.

Susiati, lye, R. (2018). Kajian Geografi Bahasa dan Dialek di Sulawesi Tenggara: Analisis Dialektometri. Gramatika: Jurnal IImiah Kebahasaan Dan Kesastraan, 6(2), 137-151. https://doi.org/10.31813/gramatika/6.2.2018.154.137--151

Susiati, S., lye, R., \& S. (2019). Hot Potatoes Multimedia Applications in Evaluation of Indonesian Learning In SMP Students in Buru District. ELS Journal on Interdisciplinary Studies in Humanities, 2(4), 556-570. 